REGARDS

SUR LECONOMIE ALLEMANDE

BULLETIN ECONOMIQUE DU CIRAC

\section{Regards sur l'économie allemande}

Bulletin économique du CIRAC

$70 \mid 2005$

Varia

\title{
[56 Ethique
}

\section{(2) OpenEdition}

1 Journals

Édition électronique

URL : http://journals.openedition.org/rea/2373

DOI : 10.4000/rea.2373

ISBN : 978-2-8218-0836-2

ISSN : $1965-0787$

Éditeur

CIRAC

Édition imprimée

Date de publication : 1 mars 2005

ISSN : 1156-8992

\section{Référence électronique}

《膯 Ethique », Regards sur l'économie allemande [En ligne], 70 | mars 2005, mis en ligne le 16 décembre 2008, consulté le 22 septembre 2020. URL : http://journals.openedition.org/rea/2373 ; DOI : https:// doi.org/10.4000/rea.2373

Ce document a été généré automatiquement le 22 septembre 2020.

(c) CIRAC 


\section{Fo Ethique}

\section{RÉFÉRENCE}

BRINK Alexander, KARITZKI Olaf, Unternehmensethik in turbulenten Zeiten.

Wirtschaftsführer über Ethik im Management, Haupt Verlag, Berne/Stuttgart/

Vienne, 2004, $380 \mathrm{p}$.

BRINK Stefan, WOLFF Heinrich Amadeus (ed.), Gemeinwohl und Verantwortung.

Festschrift für Hans Herbert von Arnim zum 65. Geburtstag, Duncker \& Humblot, Berlin, 2004, $852 \mathrm{p}$.

ARNOLD Volker (ed.), Wirtschaftsethische Perspektiven VII. Methodische Grundsatzfragen, Unternehmensethik, Verteilungsfragen, Gentechnik und Fragen der medizinischen Ethik, Coll. Schriften des Vereins für Socialpolitik, Duncker \& Humblot, Berlin, 2004, 268 p.

1 «Il n'y a pas de marché sans règles » énonce le consultant O. Karitzki (McKinsey) en introduction à un manuel sur l'éthique des affaires rassemblant les contributions de praticiens, grands patrons allemands (EADS, VW, Allianz...) ou acteurs de la macrorégulation économique et sociale (office fédéral des Cartels, syndicats). Or les mutations liées notamment à la globalisation remettent en question l'ordre établi des règles. Cela incite à un retour aux sources : celles de la morale en affaires, puissant correctif au libéralisme sauvage. A lire les contributions, on s'aperçoit combien les acteurs allemands restent attachés à leur modèle : celui de l'ordo-libéralisme. De loin plus théoriques, les contributions d'un autre ouvrage (Arnold) analysent l'équilibre entre les valeurs morales (justice, équité) et les lois économiques. L'une d'entre elles se penche sur la question d'un 'marché' d'organes; nous en avions publié une version condensée dans cette revue (Aumann/Gaertner, REA 56/02). Les valeurs centrales du libéralisme organisé se résument facilement à un couple de concepts : intérêt général et responsabilité de l'individu. Son délicat équilibre est au cœur d'un troisième ouvrage, mélanges publiés en l'honneur du juriste et économiste réputé H. H. von Arnim. (ib) 